\title{
Postnatal Stress Produces Hyperglycemia in Adult Rats Exposed to Hypoxia-Ischemia
}

\author{
RONALD J. MCPHERSON, MARCELLA MASCHER-DENEN, AND SANDRA E. JUUL
}

\author{
Department of Pediatrics [R.J.M., S.E.J.], University of Washington, Seattle, Washington 98195; Neonatology Unit [M.M.-D.], Driscoll
} Children's Hospital, Corpus Christi, Texas 78411

\begin{abstract}
Fetal or early postnatal stressors may predispose infants to develop diabetes, metabolic syndrome, or stroke. We hypothesized that postnatal stress will predispose animals to develop metabolic syndrome and impair the physiologic response to hypoxic-ischemic brain injury. We characterized the short- and long-term physiologic responses to postnatal stress by examining corticosterone (CS), glucose metabolism, and brain injury in neonatal and adult rats exposed to hypoxiaischemia (H-I). Rat pups were divided into three levels of postnatal stress from postnatal day (P) 3 to P7. All rats underwent unilateral brain injury on either P7 or P134. We measured brain injury, growth, blood pressure, urine/plasma CS, plasma leptin, insulin, and glucose before and after H-I. Postnatal stress increased neonatal CS production, exacerbated neonatal white matter injury, and was associated with adult hyperglycemia after $\mathrm{H}-\mathrm{I}$ despite increased insulin production. There were no group differences in adult weight, blood pressure, or leptin. Postnatal stress exacerbated brain injury and produced adult hyperglycemia, triggered after hypoxia exposure, consistent with the hypotheses that neonates exposed to early stress are more vulnerable to hypoxia and may be predisposed to develop metabolic syndrome in adulthood. Prolonged maternal separation produced more hyperglycemia than did brief daily handling. (Pediatr Res 66: 278-282, 2009)
\end{abstract}

$\mathrm{P}$ rolonged hospitalization in a neonatal intensive care unit is stressful because preterm infants experience prolonged isolation, gavage feedings, and multiple painful procedures. These postnatal stressors may perturb early brain development and permanently impact brain function by affecting neuronal apoptosis, neurogenesis, synaptogenesis, or vascular development. For example, neonatal isolation permanently impairs hippocampus-dependent learning and memory (1), promotes depression (2), and disrupts fear conditioning in rats (3). In addition, because prenatal events can exacerbate neonatal brain injury (4), it is possible that postnatal stress may also exacerbate neonatal H-I. Surprisingly, it is still unknown whether postnatal stress has acute or lasting effects on physiologic responses to $\mathrm{H}-\mathrm{I}$.

Heart disease, cerebrovascular disease, and diabetes are among the top causes of death in the United States (CDC), and these disease processes can be influenced by early life experiences. The observation that diabetes is more prevalent in infants born to diabetic mothers (5-7) has prompted the development of models of gestational diabetes. A variety of

Received February 9, 2009; accepted May 7, 2009.

Correspondence: Sandra Juul, MD, PhD, Division of Neonatology, Department of Pediatrics, University of Washington, Box 356320, Seattle, WA 98195; e-mail: sjuul@u.washington.edu

Supported by iNO Therapeutics and the Neonatal Biology Research Fund. experimental manipulations find that prenatal hyperglycemia leads to abnormal glucose homeostasis in the adult animal $(8-11)$. Moreover, experimental IUGR produces defects in insulin secretion and hyperglycemia in the exposed adult rats $(12,13)$. The fact that prenatal exposure to dexamethasone increases fetal hepatic glucocorticoid receptor expression and produces adult hyperglycemia in rats strongly suggests that fetal stress may program adult function (14). Although our laboratory has found adult cognitive deficits in rodents exposed to postnatal stress $(15,16)$, we have yet to examine the effects of postnatal stress on adult glucose metabolism.

We hypothesized that postnatal stress would disrupt glucose metabolism and produce adult hyperglycemia. We also hypothesized that postnatal stress would exacerbate the brain injury due to neonatal H-I. In addition, we tested whether postnatal stressinduced effects are dose dependent by comparing brief handling and prolonged maternal separation. Lastly, to model some of the indices that define human metabolic syndrome, we measured corticosterone (CS), glucose, and insulin before and after H-I in neonatal and adult rats as well as adult weight, blood pressure, and plasma leptin. This study further characterizes the short- and long-term effects of postnatal stressors. An improved understanding of the consequences of postnatal stress may reveal important therapeutic opportunities.

\section{METHODS}

\begin{abstract}
Animals. The University of Washington IACUC approved all animal procedures. Pregnant Sprague-Dawley rats were purchased from Harlan. Birth was recorded as postnatal day $1(\mathrm{P} 1)$, and pups were assigned to treatment groups on P3. Neonatal rats were housed in the laboratory and adults were transferred to a vivarium facility.

Neonatal treatment groups. Postnatal stress procedures were modified from our published model (15). Three levels of postnatal stress were applied from P3 to P7: 1) controls were dam reared and were not handled except for weekly cage cleaning; 2) brief separation/pain involved temporary $(0.5 \mathrm{~h} / \mathrm{d})$ maternal separation during which the animals were weighed and injected with $50 \mu \mathrm{L}$ saline s.c. to simulate procedural pain; 3) prolonged separation/pain involved weighing, isolation into cups in a veterinary warmer for $8 \mathrm{~h} / \mathrm{d}$ with three gavage feedings (0.1 to $0.3 \mathrm{~mL} /$ feeding) of rat milk substitute (17) and a saline injection.

Unilateral brain injury. The right common carotid artery (CCA) was ligated, and the animals were exposed to hypoxia. Neonatal rat lesions $(n=151)$ were performed on P7, and the pups were killed $72 \mathrm{~h}$ later. Adult lesions $(n=75)$ occurred on P134, and the rats were killed 2 weeks later. During surgery, rats were anesthetized ( $2.5 \%$ isoflurane), the CCA cauterized, and were exposed to $8 \% \mathrm{O}_{2}$ for either $120 \mathrm{~m}$ (neonates $35^{\circ} \mathrm{C}$ ) or $60 \mathrm{~m}$ (adults room temperature) $1 \mathrm{~h}$ later.
\end{abstract}

Abbreviations: CCA, common carotid artery; CS, corticosterone; H-I, hypoxia-ischemia; $\mathbf{P}$, postnatal day 
Physiologic measures. Dam-reared controls were handled minimally and only weighed on P10. Other groups were weighed daily. Mortalities occurred during postnatal stress, surgery, or after lesion.

Blood glucose and plasma insulin, leptin, CS (adults), and urine CS (neonates) concentrations were measured. Adults tail vein samples were collected before CCA surgery and at death. Plasma was prepared, and all samples were frozen at $-80^{\circ} \mathrm{C}$ until assayed. In neonates, urine was obtained immediately before CCA surgery and shortly after recovery from hypoxia exposure on P7. Urine was obtained after tactile stimulation of the genital region or by needle aspiration from the bladder. Repeated urine sampling was nonlethal. A baseline for neonatal rat urine CS concentrations was determined using six nonstudy rats. ELISA kits were used to quantify CS (DSLabs Inc.), insulin (Bachem), and leptin (SPIbio). Blood glucose concentrations were measured at death using a One Touch Ultra meter (LifeScan Inc.). Blood pressure was measured at P120 using a noninvasive tail cuff (Kent Sci.).

Brain injury scoring. All rats were killed by overdose with Euthasol $(2.2$ $\mathrm{mL} / \mathrm{kg}$ i.p.; Delmarva Labs, Inc). Brains were removed, weighed, and grossly examined for injury and scored on a 5-point scale: $0=$ no injury; $1=$ mild edema/atrophy with $<25 \%$ lesion; $2=$ moderate atrophy, $25-50 \% ; 3=$ severe atrophy with cystic cavitation, $50-75 \%$; and $4=$ severe atrophy, $>75 \%$. Coronal blocks containing hippocampus were cut, fixed, and processed to H\&E stain 5 $\mu \mathrm{M}$ sections. Blinded images were captured for each hemisphere and scored by two individuals. The area of hippocampus was outlined, and the injured/uninjured hemisphere ratio was calculated using software (AnalySIS). In neonates, the cortex, thalamus, and internal capsule were also scored $0-4$ for structural injury or gliosis as previously described (18-20).

Statistical analysis. ANOVA or nonparametric analyses and post hoc comparisons were made using SPSS software. Levene's test for homogeneity was evaluated. Parametric data were expressed as means and include SE (SEM). Nonparametric Mann-Whitney $U$ tests with Bonferroni corrections were used. Two-tailed post hoc tests included $t$ test (two groups) or Dunnett's (three groups). $\chi^{2}$ test compared rates. Alpha was 0.05 (uncorrected).

\section{RESULTS}

Neonatal measures. We implemented a procedure to permit longitudinal measurement of CS production in neonatal rats. Figure 1 illustrates the daily CS concentrations measured from urine samples repeatedly collected from P2 to P17. Repeated sampling of neonatal urine worked well, and CS concentrations were detectable and exhibited an abrupt increase from P10 onward. Next, we sought to identify whether the handling and separation procedures had acute effects on neonatal rat CS production. Figure 2 shows the urine CS concentrations measured from a subset of rats 45,120 , and $300 \mathrm{~m}$ after exposure to brief or prolonged separation on P6. Urine from prolonged-separation rats contained higher concentrations of CS than rats given brief

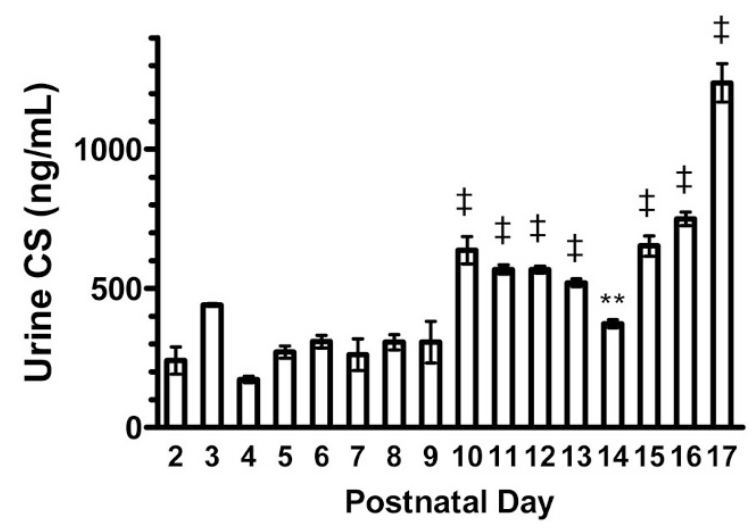

Figure 1. Mean ( \pm SEM) CS concentrations in neonatal rat urine sampled daily from P2 to P17. These data define the expected range for urine CS values in neonatal rats. Repeated measures (RM)-ANOVA found effects of time $\left(F_{15}=24.5, p<0.001\right.$ and Dunnett's post hoc comparisons to $\mathrm{P} 2$ are indicated as $\ddagger p<0.001$ and $* * p<0.05 . n=3-6 /$ time point.

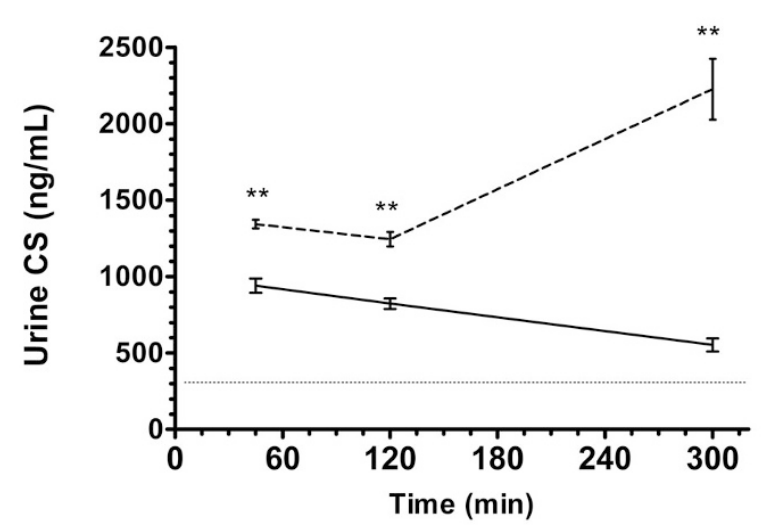

Figure 2. Mean ( \pm SEM) urine CS concentrations measured on P6 from rats after exposure to brief handling (solid line) or during prolonged maternal separation (dashed line). These data identify that prolonged separation is more stressful than brief handling as indicated by an immediate increases in CS production. RM-ANOVA found effects of time $\left(F_{2,8}=12.8, p<0.01\right)$ and separation $\left(F_{1,4}=77.1, p<0.001\right)$ and a separation $\times$ time interaction $\left(F_{1,4}=45.8, p<0.01\right)$ with $n=3$ /group. Post hoc comparisons between the groups are indicated $(* * p<0.01)$. The horizontal dotted line at $308 \mathrm{ng} / \mathrm{mL}$ is the baseline P6 CS level from Figure 1.

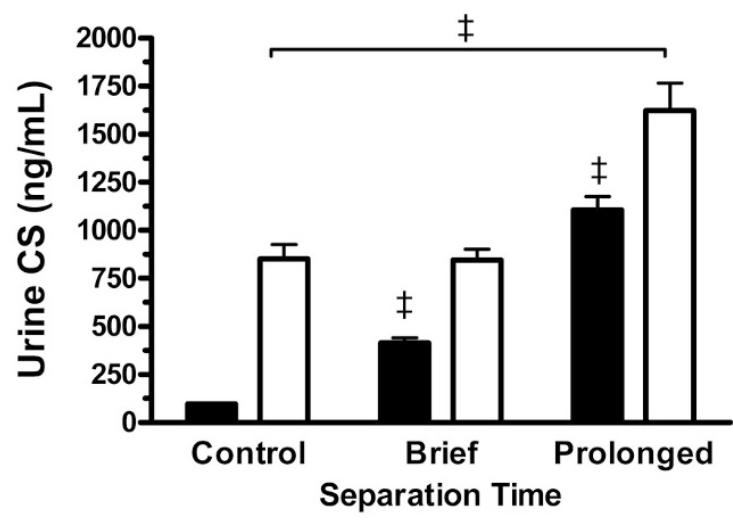

Figure 3. Mean ( \pm SEM) urine CS concentrations from groups of $\mathrm{P} 7$ rats before (filled bars) and shortly after (unfilled bars) unilateral hypoxicischemic lesion. RM-ANOVA $2 \times 3$ found significant effects of hypoxicischemic lesion $\left(F_{1,34}=219.8, p<0.001\right)$ and separation $\left(F_{2,33}=47.9, p<\right.$ $0.001)$ and a separation $\times$ lesion interaction $\left(F_{2,33}=6.5, p<0.01\right)$. Five days (P3-P7) of brief handling or prolonged separation increased all the before lesion values compared with control. Urine CS was increased after lesion for all groups $(p<0.001)$. As indicated by the bracket, the after lesion urine CS values for the prolonged separation group were significantly higher than control. There were no differences due to sex, so data from males and females were combined. Dunnett's post hoc comparisons to controls at the same before/after time are indicated as $\ddagger p<0.001 . n=12 /$ group.

separation, indicating that the increased severity of neonatal maternal separation quickly produces a greater CS response. Figure 3 compares the mean urine CS concentrations in P7 rats, before and after H-I, and illustrates that postnatal stress elevated basal urine CS before CCA ligation and H-I triggered an acute CS response that was elevated by prolonged separation.

We examined whether postnatal stress modulated neonatal brain injury on P10. The control group showed mild injury (mean brain injury score \pm SEM: $1.1 \pm 0.2, n=22$ ), and there were no effects of stress on gross brain injury. Brain injury scores were $0.8 \pm 0.4, n=14$ and $1.1 \pm 0.5, n=12$ in the brief and prolonged separation groups, respectively. 
There were also no differences in hippocampal injured/ uninjured area ratios (range $78-90 \%$ of the intact hemisphere) between the treatment groups (data not shown). Figure 4 displays the injury scores assigned in neonatal cortex (top panel), thalamus (center panel), and internal capsule (bottom panel). There were no group differences in cortical injury scores, and this is consistent with the gross injury and hippocampal volume data. However, postnatal stress increased the degree of injury in thalamus and internal capsule. These data demonstrate that gross injury scores may only provide information about cortical injury and may not reflect internal brain injury. These data also indicate that postnatal stress can specifically exacerbate certain types of hypoxic-ischemic injury. In particular, the white matter of the internal capsule seems to be very sensitive to neonatal handling and separation.

There were no differences between the groups for neonatal mortality, neonatal growth, or neonatal brain weights at death (data not shown).

Adult measures. Rats were lesioned at P135 and killed 2 weeks later to identify whether postnatal stress altered adult physiologic responses to H-I. Apart from expected sex differences, there were no group differences for adult body weights (means \pm SEM, male: $374 \pm 6 \mathrm{~g}, n=19$; female: $255 \pm 3 \mathrm{~g}$, $n=24$ ) or blood pressures (means \pm SEM male: $158 / 115 \pm 3 / 2$, $n=19$; female: $137 / 97 \pm 3 / 2, n=24$ ) measured 2 weeks before lesion at P120. Comparing measurements before and after H-I, plasma glucose and insulin, but not CS and leptin, were significantly elevated after lesion. Table 1 lists the plasma glucose for adult rats before and after H-I. Hypoxia-ischemia elevated glucose in all groups, and this effect was significantly greater in stressed rats compared with controls. There were no differences due to sex for plasma glucose. Table 2 shows that plasma insulin concentrations were also elevated postlesion; however, there were no differences between the treatment groups. Table 3 lists the plasma corticosterone and Table 4 lists the plasma leptin concentrations measured before/after lesion, and there were no group differences in either of these indices before/after lesion. Similar to the neonatal data, there were no differences in the degree of gross brain injury or in hippocampal injured/uninjured area ratios (range $69-79 \%$ of the intact hemisphere) between the groups (data not shown).

\section{DISCUSSION}

This experiment exposed rats to three levels of postnatal stress and then evaluated physiologic responses to H-I at both neonatal and adult ages. The goal was to understand whether postnatal stress produces effects that interact with H-I. The
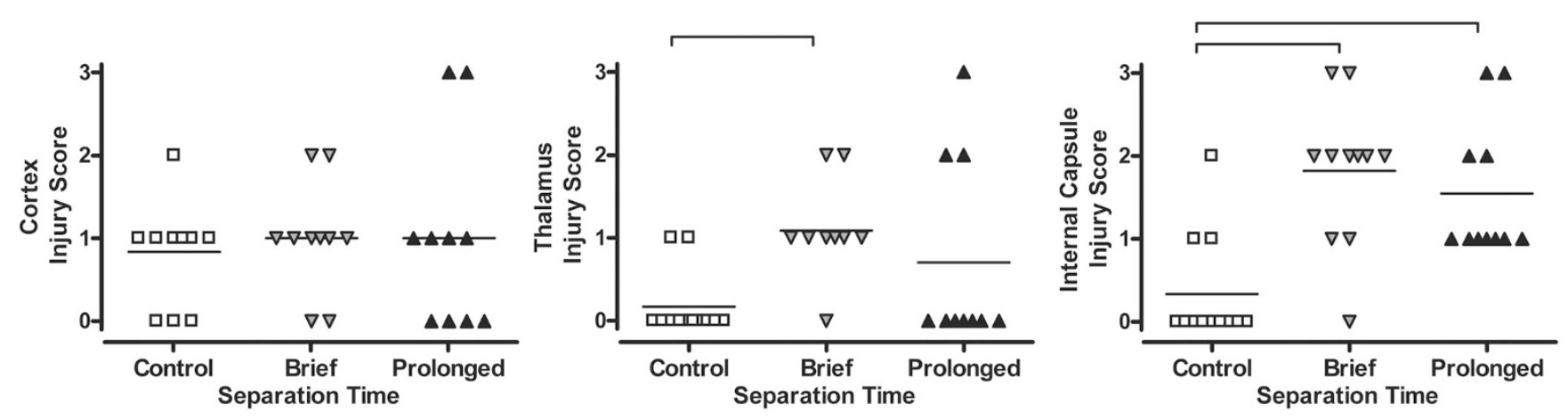

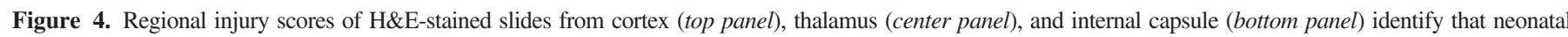

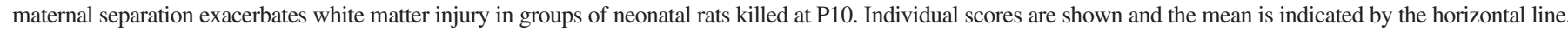

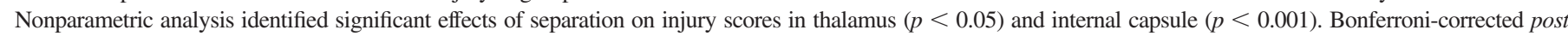
hoc $t$ tests compared brief and prolonged separation to control and significant differences are indicated by the brackets. $n=10-12 /$ group.

Table 1. Mean $\pm \operatorname{SEM}(\mathrm{N})$ adult plasma glucose $(\mathrm{mg} / \mathrm{dL})$ before and after hypoxic-ischemic lesion

\begin{tabular}{|c|c|c|c|c|}
\hline \multirow[b]{2}{*}{ Separation time } & \multicolumn{2}{|c|}{ Female } & \multicolumn{2}{|c|}{ Male } \\
\hline & Before lesion & After lesion* & Before lesion & After lesion* \\
\hline Control & $106.3 \pm 9.4(8)$ & $139.9 \pm 6.8(7)$ & $102.2 \pm 4.6(6)$ & $143.3 \pm 4.8(6)$ \\
\hline Brief & $98.1 \pm 5.7(8)$ & $167 \pm 7.4(6) \dagger$ & $108.7 \pm 6.5(6)$ & $154.8 \pm 11(5)$ \\
\hline Prolonged & $108.1 \pm 6.3(8)$ & $196.7 \pm 8.3(7) \ddagger$ & $112.3 \pm 8(7)$ & $194.3 \pm 8.2(7) \ddagger$ \\
\hline
\end{tabular}

ANOVA found effects of lesion $\left(F_{1,32}=316.9, p<0.001\right)$, group $\left(F_{2,32}=15.2, p<0.001\right)$, and a lesion by group interaction $\left(F_{2,32}=14.6, p<0.001\right)$. All glucose values were increased after lesion (* $p<0.001)$. Significant group comparisons to control are indicated $(\dagger p<0.05, \ddagger p<0.001)$.

Table 2. Mean $\pm \operatorname{SEM}(N)$ adult plasma insulin $(\mathrm{pg} / \mathrm{mL})$ before and after hypoxic-ischemic lesion

\begin{tabular}{cccccc}
\hline & \multicolumn{2}{c}{ Female } & & \multicolumn{2}{c}{ Male } \\
\cline { 2 - 3 } Separation time & Before lesion & After lesion* & & Before lesion & After lesion* \\
\hline Control & $909.6 \pm 150.8(8)$ & $2379.9 \pm 400.6(8)$ & & $1254.1 \pm 302(5)$ & $40.2 \pm 426.2(5)$ \\
Brief & $1025.1 \pm 204.2(8)$ & $2123.4 \pm 342.8(8)$ & & $897.9 \pm 166.4(6)$ & $4040.9 \pm 1631.9(6)$ \\
Prolonged & $1233.5 \pm 214.2(8)$ & $2458.1 \pm 297(8)$ & & $1224.8 \pm 278.7(7)$ & $2427.3 \pm 441.3(7)$ \\
\hline
\end{tabular}

ANOVA found insulin increased after lesion $\left(F_{1,36}=28.1,{ }^{*} p<0.001\right)$ but there were no group differences. 
Table 3. Mean $\pm \operatorname{SEM}(N)$ adult plasma corticosterone $(\mathrm{ng} / \mathrm{mL})$ before and after hypoxic-ischemic lesion

\begin{tabular}{|c|c|c|c|c|}
\hline \multirow[b]{2}{*}{ Separation time } & \multicolumn{2}{|c|}{ Female } & \multicolumn{2}{|c|}{ Male* } \\
\hline & Before lesion & After lesion & Before lesion & After lesion \\
\hline Control & $784.5 \pm 126.4(8)$ & $592.7 \pm 129.6(8)$ & $211.4 \pm 44.2(5)$ & $348.8 \pm 50.3(5)$ \\
\hline Brief & $798 \pm 151.9(8)$ & $1109.6 \pm 222.9(8)$ & $341.6 \pm 49.1(6)$ & $523.4 \pm 297.8(6)$ \\
\hline Prolonged & $976.6 \pm 119.1(8)$ & $969.6 \pm 179(8)$ & $201.4 \pm 40.1(7)$ & $679.1 \pm 269.3(7)$ \\
\hline
\end{tabular}

ANOVA found sex differences $\left(F_{1,36}=17.9,{ }^{*} p<0.001\right)$ but there were no group differences.

Table 4. Mean $\pm \operatorname{SEM}(N)$ adult plasma leptin $(\mathrm{pg} / \mathrm{mL})$ before and after hypoxic-ischemic lesion

\begin{tabular}{|c|c|c|c|c|}
\hline \multirow[b]{2}{*}{ Separation time } & \multicolumn{2}{|c|}{ Female } & \multicolumn{2}{|c|}{ Male } \\
\hline & Before lesion & After lesion & Before lesion & After lesion \\
\hline Control & $2799.4 \pm 432.8(8)$ & $1848.4 \pm 522.8(8)$ & $3053.7 \pm 316.2(5)$ & $3292.4 \pm 429.2(5)$ \\
\hline Brief & $2266.1 \pm 251.7(8)$ & $2086.5 \pm 475.7(8)$ & $2031 \pm 540.9(6)$ & $1848.7 \pm 371.6(6)$ \\
\hline Prolonged & $2856.7 \pm 375(8)$ & $4317.2 \pm 2340.3(8)$ & $3073.2 \pm 162.3(7)$ & $3444.5 \pm 431(7)$ \\
\hline
\end{tabular}

There were no differences due to lesion, group, or sex for leptin values.

major findings of this experiment are as follows: 1) while both brief and prolonged daily handling are stressful to neonatal animals, prolonged maternal separation is more stressful than brief separation as evidenced by increased neonatal CS production; 2) postnatal stress changes the vulnerability of neonatal animals to subsequent white matter and deep gray matter injury; and 3) postnatal stress alters adult glucose homeostasis in a dose-dependent manner.

Experiments examining effects of neonatal stress recognize that early life stress may produce life-long effects that increase risk for certain types of adult disease $(13,21,22)$. Most notably, maternal separation stress enhances the hypothalamicpituitary-adrenal stress response as indicated by circulating CS concentrations (23-27). Urine CS measurements have previously been reported as a reliable method by which to assess stress in adult rats (28), but no such data exists for neonatal animals. We now report that urine CS concentrations are also a valid, reliable, minimally invasive (and nonlethal) method for measurement of the stress response in tiny neonatal rodents. We have shown that CS production increases during early development, more prolonged separation induces greater CS production than does brief handling, and postnatal stress elevates CS production during the neonatal period. We note also that the abrupt increase in urine CS detected after P10 agrees with the observation that mouse plasma CS increases on P12 (29) but challenges the interpretation that the later postnatal increases in plasma CS are due to decreased clearance (30). Although postnatal stress elevated CS production acutely, this effect did not persist into adulthood, and these new adult data agree with our prior adult plasma CS measurements (15).

The overproduction of steroids during fetal or neonatal stress may reprogram organ tissues and produce abnormalities in adult organ function or metabolism (31). The metabolic abnormalities may be changes in basal function or changes in function during physiologic challenges such as H-I (32). If true, postnatal stress may alter susceptibility to later injury. To examine these possibilities, we measured weight and blood pressure in adults and also measured adult plasma glucose, insulin, CS, and leptin before/after exposure to H-I. There were no group differences in weight, blood pressure, leptin, or
CS and thus no evidence of obesity, hypercortisolemia, or hypertension in the adult rat exposed to 1 week of brief or prolonged postnatal stress.

However, adult hypoxic-ischemic lesion was associated with elevated glucose in rats that had experienced prolonged postnatal stress, but not in controls. Given that insulin production increased after lesion in all groups, it is possible that the postlesion glucose elevation reveals an underlying insulin resistance. By this interpretation, we have identified that postnatal stress induces mild insulin resistance, which manifests after an adult hypoxic-ischemic insult. We qualify this interpretation by pointing out that the glucose was elevated beyond the maximum of the normal published range (33), but still below the $250 \mathrm{mg} / \mathrm{dL}$ cutoff for hyperglycemia in rats. These data complement reports demonstrating that experimental IUGR produces progressive adult insulin resistance and hyperglycemia in rats $(12,13)$. Our postlesion glucose values at $21 \mathrm{wk}$ of age closely match the glucose values seen at $15 \mathrm{wk}$ of age in the IUGR model. Our findings also support observations that perinatal steroid exposure produces hyperglycemia in animals $(14,34)$ and humans $(35)$, and thereby strengthen the concern that perinatal glucocorticoids program adult disease states (36). Specifically, our findings are consistent with the hypothesis that neonates exposed to early stress may be predisposed to develop a prediabetic syndrome in adulthood.

We also examined whether neonatal brain injury was affected by prior postnatal stress. Although there were no effects of prolonged stress on neonatal mortality, growth, brain weight, or gross injury scores after H-I, there were effects on regional brain injury scores. In particular, neonatal stress increased the susceptibility to white matter injury in the internal capsule and to thalamic injury. Perhaps the cognitive deficits seen after neonatal pain and stress in animal models $(15,16,37,38)$ and recently in preterm infants $(39)$ are related to increased vulnerability of specific brain regions.

The observation that postnatal stress enhances white matter vulnerability is particularly salient for preterm infants. Between 25 and $48 \%$ of extremely low birth weight infants have substantial neurodevelopmental impairment (neurosensory abnormality and/or mental developmental index score $<70$ ) 
(40-43). Some preterm infants exhibit reduced MRI gray and/or white matter volume at term corrected age when no known risk factors were present (44-46). Prolonged postnatal steroid therapy is a risk factor for cerebral palsy (47). We speculate that the increased steroid production associated with neonatal stress may exacerbate white matter vulnerability and contribute to periventricular leukomalacia and poor neurodevelopmental outcomes. There is still concern that neonatal pain and stress may contribute to abnormal neurodevelopment in preterm infants $(48-50)$. In summary, the data presented support concerns about reducing neonatal stress to reduce risk of neonatal brain injury and adult diabetes.

\section{Acknowledgment. We thank Kelly Ledbetter for excellent} technical assistance.

\section{REFERENCES}

1. Louvart H, Maccari S, Darnaudery M 2005 Prenatal stress affects behavioral reactivity to an intense stress in adult female rats. Brain Res 1031:67-73

2. Matthews K, Robbins TW 2003 Early experience as a determinant of adult behavioural responses to reward: the effects of repeated maternal separation in the rat. Neurosci Biobehav Rev 27:45-55

3. Weiss IC, Pryce CR, Jongen-Relo AL, Nanz-Bahr NI, Feldon J 2004 Effect of social isolation on stress-related behavioural and neuroendocrine state in the rat. Behav Brain Res 152:279-295

4. Wang X, Hagberg H, Nie C, Zhu C, Ikeda T, Mallard C 2007 Dual role of intrauterine immune challenge on neonatal and adult brain vulnerability to hypoxiaischemia. J Neuropathol Exp Neurol 66:552-561

5. Rizzo TA, Dooley SL, Metzger BE, Cho NH, Ogata ES, Silverman BL 1995 Prenatal and perinatal influences on long-term psychomotor development in offspring of diabetic mothers. Am J Obstet Gynecol 173:1753-1758

6. Silverman BL, Metzger BE, Cho NH, Loeb CA 1995 Impaired glucose tolerance in adolescent offspring of diabetic mothers. Relationship to fetal hyperinsulinism. Diabetes Care 18:611-617

7. Pettitt DJ, Aleck KA, Baird HR, Carraher MJ, Bennett PH, Knowler WC 1988 Congenital susceptibility to NIDDM. Role of intrauterine environment. Diabetes 37:622-628

8. Aerts L, Sodoyez-Goffaux F, Sodoyez JC, Malaisse WJ, Van Assche FA 1988 The diabetic intrauterine milieu has a long-lasting effect on insulin secretion by B cells and on insulin uptake by target tissues. Am J Obstet Gynecol 159:1287-1292

9. Cuezva JM, Burkett ES, Kerr DS, Rodman HM, Patel MS 1982 The newborn of diabetic rat. I. Hormonal and metabolic changes in the postnatal period. Pediatr Res 16:632-637

10. Eriksson U, Andersson A, Efendic S, Elde R, Hellerstrom C 1980 Diabetes in pregnancy: effects on the foetal and newborn rat with particular regard to body weight, serum insulin concentration and pancreatic contents of insulin, glucagon, and somatostatin. Acta Endocrinol (Copenh) 94:354-364

11. Gauguier D, Bihoreau MT, Ktorza A, Berthault MF, Picon L 1990 Inheritance of diabetes mellitus as consequence of gestational hyperglycemia in rats. Diabetes 39:734-739

12. Boloker J, Gertz SJ, Simmons RA 2002 Gestational diabetes leads to the development of diabetes in adulthood in the rat. Diabetes 51:1499-1506

13. Simmons RA, Templeton LJ, Gertz SJ 2001 Intrauterine growth retardation leads to the development of type 2 diabetes in the rat. Diabetes 50:2279-2286

14. Nyirenda MJ, Lindsay RS, Kenyon CJ, Burchell A, Seckl JR 1998 Glucocorticoid exposure in late gestation permanently programs rat hepatic phosphoenolpyruvate carboxykinase and glucocorticoid receptor expression and causes glucose intolerance in adult offspring. J Clin Invest 101:2174-2181

15. McPherson RJ, Gleason C, Mascher-Denen M, Chan M, Kellert B, Juul SE 2007 A new model of neonatal stress which produces lasting neurobehavioral effects in adult rats. Neonatology 92:33-41

16. Boasen JF, McPherson RJ, Hays SL, Juul SE, Gleason CA 2008 Neonatal stress or morphine treatment alters adult mouse conditioned place preference. Neonatology 95:230-239

17. Messer M, Thoman EB, Galofre A, Dallman T, Dallman PR 1969 Artificial feeding of infant rats by continuous gastric infusion. J Nutr 98:404-410

18. Dingley J, Tooley J, Porter H, Thoresen M 2006 Xenon provides short-term neuroprotection in neonatal rats when administered after hypoxia-ischemia. Stroke 37:501-506

19. Nakajima W, Ishida A, Lange MS, Gabrielson KL, Wilson MA, Martin LJ, Blue ME, Johnston MV 2000 Apoptosis has a prolonged role in the neurodegeneration after hypoxic ischemia in the newborn rat. J Neurosci 20:7994-8004

20. Tsuji M, Wilson MA, Lange MS, Johnston MV 2004 Minocycline worsens hypoxicischemic brain injury in a neonatal mouse model. Exp Neurol 189:58-65

21. Barker DJ, Osmond C, Golding J, Kuh D, Wadsworth ME 1989 Growth in utero, blood pressure in childhood and adult life, and mortality from cardiovascular disease. BMJ 298:564-567
22. Barker DJ, Shiell AW, Barker ME, Law CM 2000 Growth in utero and blood pressure levels in the next generation. J Hypertens 18:843-846

23. Levine S, Huchton DM, Wiener SG, Rosenfeld P 1991 Time course of the effect of maternal deprivation on the hypothalamic-pituitary-adrenal axis in the infant rat. Dev Psychobiol 24:547-558

24. D'Amato FR, Cabib S, Puglisi-Allegra S, Patacchioli FR, Cigliana G, Maccari S, Angelucci L 1992 Effects of acute and repeated exposure to stress on the hypothalamo-pituitary-adrenocortical activity in mice during postnatal development. Horm Behav 26:474-485

25. Ogawa T, Mikuni M, Kuroda Y, Muneoka K, Mori KJ, Takahashi K 1994 Periodic maternal deprivation alters stress response in adult offspring: potentiates the negative feedback regulation of restraint stress-induced adrenocortical response and reduces the frequencies of open field-induced behaviors. Pharmacol Biochem Behav 49:961967

26. Parfitt DB, Levin JK, Saltstein KP, Klayman AS, Greer LM, Helmreich DL 2004 Differential early rearing environments can accentuate or attenuate the responses to stress in male C57BL/6 mice. Brain Res 1016:111-118

27. Schmidt MV, Levine S, Alam S, Harbich D, Sterlemann V, Ganea K, de Kloet ER, Holsboer F, Muller MB 2006 Metabolic signals modulate hypothalamic-pituitaryadrenal axis activation during maternal separation of the neonatal mouse. J Neuroendocrinol 18:865-874

28. Bamberg E, Palme R, Meingassner JG 2001 Excretion of corticosteroid metabolites in urine and faeces of rats. Lab Anim 35:307-314

29. Diez JA, Sze PY, Ginsburg BE 1976 Postnatal development of mouse plasma and brain corticosterone levels: new findings contingent upon the use of a competitive protein-binding assay. Endocrinology 98:1434-1442

30. Schroeder RJ, Henning SJ 1989 Roles of plasma clearance and corticosteroidbinding globulin in the developmental increase in circulating corticosterone in infant rats. Endocrinology 124:2612-2618

31. Fowden AL, Forhead AJ 2004 Endocrine mechanisms of intrauterine programming. Reproduction 127:515-526

32. Li G, Bae S, Zhang L 2004 Effect of prenatal hypoxia on heat stress-mediated cardioprotection in adult rat heart. Am J Physiol Heart Circ Physiol 286:H1712 H1719

33. Stender RN, Engler WJ, Braun TM, Hankenson FC 2007 Establishment of blood analyte intervals for laboratory mice and rats by use of a portable clinical analyzer. J Am Assoc Lab Anim Sci 46:47-52

34. Lindsay RS, Lindsay RM, Waddell BJ, Seckl JR 1996 Prenatal glucocorticoid exposure leads to offspring hyperglycaemia in the rat: studies with the 11 betahydroxysteroid dehydrogenase inhibitor carbenoxolone. Diabetologia 39:1299-1305

35. Koivisto M, Peltoniemi OM, Saarela T, Tammela O, Jouppila P, Hallman M 2007 Blood glucose level in preterm infants after antenatal exposure to glucocorticoid. Acta Paediatr 96:664-668

36. Seckl JR, Meaney MJ 2004 Glucocorticoid programming. Ann N Y Acad Sci 1032:63-84

37. Brunson KL, Kramar E, Lin B, Chen Y, Colgin LL, Yanagihara TK, Lynch G, Baram TZ 2005 Mechanisms of late-onset cognitive decline after early-life stress. J Neurosci 25:9328-9338

38. Kosten TA, Karanian DA, Yeh J, Haile CN, Kim JJ, Kehoe P, Bahr BA 2007 Memory impairments and hippocampal modifications in adult rats with neonatal isolation stress experience. Neurobiol Learn Mem 88:167-176

39. Grunau RE, Whitfield MF, Petrie-Thomas J, Synnes AR, Cepeda IL, Keidar A, Rogers M, Mackay M, Hubber-Richard P, Johannesen D 2009 Neonatal pain, parenting stress and interaction, in relation to cognitive and motor development at 8 and 18 months in preterm infants. Pain 143:138-146

40. La Pine TR, Jackson JC, Bennett FC 1995 Outcome of infants weighing less than 800 grams at birth: 15 years' experience. Pediatrics 96:479-483

41. Vohr BR, Wright LL, Dusick AM, Perritt R, Poole WK, Tyson JE, Steichen JJ, Bauer CR, Wilson-Costello DE, Mayes LC; Neonatal Research Network 2004 Center differences and outcomes of extremely low birth weight infants. Pediatrics 113:781-789

42. Wilson-Costello D, Friedman H, Minich N, Fanaroff AA, Hack M 2005 Improved survival rates with increased neurodevelopmental disability for extremely low birth weight infants in the 1990s. Pediatrics 115:997-1003

43. Eichenwald EC, Stark AR 2008 Management and outcomes of very low birth weight. N Engl J Med 358:1700-1711

44. Srinivasan L, Dutta R, Counsell SJ, Allsop JM, Boardman JP, Rutherford MA, Edwards AD 2007 Quantification of deep gray matter in preterm infants at termequivalent age using manual volumetry of 3-tesla magnetic resonance images. Pediatrics 119:759-765

45. Cheong JL, Hunt RW, Anderson PJ, Howard K, Thompson DK, Wang HX, Bear MJ, Inder TE, Doyle LW 2008 Head growth in preterm infants: correlation with magnetic resonance imaging and neurodevelopmental outcome. Pediatrics 121:e1534-e1540

46. Mewes AU, Huppi PS, Als H, Rybicki FJ, Inder TE, McAnulty GB, Mulkern RV, Robertson RL, Rivkin MJ, Warfield SK 2006 Regional brain development in serial magnetic resonance imaging of low-risk preterm infants. Pediatrics 118:23-33

47. Jobe AH 2004 Postnatal corticosteroids for preterm infants- do what we say, not what we do. N Engl J Med 350:1349-1351

48. Anand KJ 2000 Effects of perinatal pain and stress. Prog Brain Res 122:117-129

49. Grunau R 2002 Early pain in preterm infants. A model of long-term effects. Clin Perinatol 29:373-394, vii-viii

50. Maroney DI 2003 Recognizing the potential effect of stress and trauma on premature infants in the NICU: how are outcomes affected? J Perinatol 23:679-683 